\title{
A retrospective cohort study on European Reference Network for Rare Vascular Diseases 5 outcome measures for Hereditary Haemorrhagic Telangiectasia in Denmark
}

\section{Troels Hvelplund}

University of Southern Denmark Faculty of Health Sciences: Syddansk Universitet Det

Sundhedsvidenskabelige Fakultet https://orcid.org/0000-0001-6853-4955

Bibi Lange

Odense University Hospital: Odense Universitetshospital

\section{Susanne Djernes Bird}

Odense University Hospital: Odense Universitetshospital

\section{Malene Korsholm}

Odense University Hospital: Odense Universitetshospital

Anette Kjeldsen ( $\boldsymbol{\nabla}$ anette.kjeldsen@rsyd.dk)

Odense University Hospital https://orcid.org/0000-0003-0593-6302

\section{Research}

Keywords: Hereditary Haemorrhagic Telangiectasia, VASCERN, PAVM screening, iron deficiency

Posted Date: October 11th, 2021

DOI: https://doi.org/10.21203/rs.3.rs-948431/v1

License: (c) (i) This work is licensed under a Creative Commons Attribution 4.0 International License. Read Full License

Version of Record: A version of this preprint was published at Orphanet Journal of Rare Diseases on January 6th, 2022. See the published version at https://doi.org/10.1186/s13023-021-02160-1. 


\section{Abstract}

\section{Background}

Hereditary Haemorrhagic Telangiectasia ( $\mathrm{HHT})$ is an autosomal dominant disorder characterized by several clinical symptoms including epistaxis, arteriovenous malformations (AVM), and telangiectasia. In 2018, European Reference Network for Rare Vascular Diseases (VASCERN) recommended five outcome measures for HHT-patients to guide health care providers, some with limited experience in treating HHT, and thereby maximizing the number of HHT-patients receiving good care. The outcome measures cover the following aspects: 1) $90 \%$ of the patients should receive a pulmonary AVM (PAVM) screening; 2 ) $90 \%$ of the patients should receive written advice on nosebleed; 3 ) $70 \%$ should be assessed for iron deficiency; 4) $100 \%$ of the patients should receive written advice on antibiotic (AB) prophylaxis prior to dental and surgical procedures, and; 5) 100\% of relevant patients should receive written advice on pregnancy. We have introduced the outcome measures as Benchmarks in our HHT-centre and wanted to evaluate the extend of implementation we have achieved. We constantly struggle to secure the best possible treatment of our HHT-patients.

\section{Methods}

The study was a non-interventional retrospective study. All data was collected from medical journals and from the Danish HHT-database.

Results

A total of $180 \mathrm{HHT}$-patients were included, all diagnosed in the period from January $1^{\text {st }} 2016$ to December $31^{\text {st }} 2020$. All patients were screened for PAVM. We could confirm that $66 \%$ of patients who had epistaxis received thoroughly advice. Assessment for iron deficiency was performed in $80 \%$ of the adult patients. Thoroughly advice on antibiotic prophylaxis was documented in $75 \%$. Thoroughly advice on pregnancy was documented in $80 \%$ of female patients $15-45$ years of age. There were no significant differences over time for any of the outcome measures.

\section{Conclusions}

The Danish HHT-centre reached the target threshold for outcome measures 1 and 3 . We could not document reaching the target thresholds for outcome measures 2, 4, and 5 . As information and education is a very important part of HHT care, we will focus on and document that all patients receive the relevant advice and as part of our care, we will in the near future implement an electronic solution with advice for HHT patients.

\section{Introduction}

Hereditary Haemorrhagic Telangiectasia $(\mathrm{HHT})$ is a rare and autosomal dominant inherited disease that affects approximately 1 out of 6,400 [1]. HHT affects growth and repair of endothelial cells in the 
capillaries and is characterized by dilation of the small capillaries (telangiectasia) in the skin and mucosa, as well as formation of arteriovenous malformations (AVM). AVM can occur in several different organs including pulmonary (PAVM), hepatic (HAVM), and cerebral (CAVM) AVMs. As a result of the change in capillary anatomy, bleeding from telangiectatic lesions in the skin and the mucous membranes often occur. Clinical manifestations of HHT include recurrent epistaxis, gastrointestinal bleeding, iron deficiency anaemia, brain abscess and focal neurological symptoms [2]. Pregnancy in female patients with $\mathrm{HHT}$ is considered a high risk pregnancy [3].

European Reference Network on Rare Vascular Diseases (VASCERN) is an EU supported collaboration among European hospitals. One of VASCERNs goals is to encourage the development of quality and safety benchmarks, and help to develop and implement best practice [4]. In 2018, VASCERN published a position statement regarding 5 outcome measures in order to maximize the number of HHT-patients receiving good care [5]. The outcome measures were evaluated as "easy to use", also for healthcare providers with limited training in how to handle HHT-patients.

The 5 outcomes cover the following areas: 1) pulmonary screening; 2) written nosebleed advice; 3 ) assessment of iron deficiency anaemia; 4) written advice on antibiotic (AB) prophylaxis prior to dental or surgical procedures, and; 5) written advice on pregnancy.

The Danish HHT-centre is located at Odense University Hospital and is a part of VASCERN. The centre is responsible for diagnostics and treatment of all HHT-patients in Denmark. Furthermore, the centre manages a database of all HHT-patients.

To our knowledge, no study has investigated the implementation of VASCERN recommendations at any hospital in Europe (appendix 1, search strategy). The aim of this study is to investigate the degree of implementation of the VASCERN 5 outcome measures for HHT-patients.

\section{Methods}

The study was a non-interventional retrospective cohort study. All data was collected from medical journals and from the national HHT-database. Data included in this study covers all patients diagnosed with HHT in the time period January $1^{\text {st }} 2016$ to December $31^{\text {st }} 2020$. Group I consisted of the patients visiting the Danish HHT-centre before the VASCERN recommendations, and group II consisted of the patients visiting the centre after the recommendations were published (February $12^{\text {th }} 2018$ ). Study data was collected from medical records and managed using Research Electronic Data Capture (REDCap) [6] access provided by OPEN[7]. HHT was diagnosed either by a molecular genetic test or clinically using the Curaçao criteria [8]. As part of the assessment of information, a small qualitative study (telephone interview) was performed in a group of newly diagnosed HHT-patients.

\section{Aim}

The objective of the study was to evaluate if: 
- At least $90 \%$ of patients had a screening for PAVM.

1. Secondary, to investigate the prevalence of PAVM among different HHT-genotypes, and if PAVMs were treated.

- At least $90 \%$ of patients received written advice on nosebleed.

- At least $70 \%$ of patients were assessed for iron deficiency anaemia.

1. Secondary, to investigate the prevalence of anemia in newly diagnosed HHT patients

- $100 \%$ of all patients with PAVM received written advice on prophylactic AB.

- $100 \%$ of patients received written advice on pregnancy.

Medical journals were scanned and categorized by TH. In case of doubt, AK was consulted to determinate the right category. For further detail information about categorization, see Appendix 2.

\section{Screening for PAVM}

At the HHT-centre OUH three screening modalities are used: first measurement of oxygen saturation, secondly a Transthoracic Contrast Echocardiography (TTCE) and if the TTCE is pathological a CTscanning of the chest is offered. If a treatable PAVM is identified the patient is referred to embolization and/or in few cases surgery. TTEC scanning is offered to all patients over the age of 12 years. If a patient has a TTEC between the age 12 and 17, a new TTEC is offered at the age of 18 years when the child is fully grown. Likewise, all women are offered a TTEC after each pregnancy.

Data regarding PAVM screening was divided into three categories: screening for PAVM was initiated; screening for PAVM was not initiated, and; PAVM was already diagnosed.

PAVM status were divided into three categories: no PAVM; PAVM, or; micro-PAVM.

\section{Need of treatment for PAVM according to HHT-genotype}

To determine HHT-genotype and treatment, existing data from the HHT-database were used. In the database the genotype of HHT-patients was categorized in four groups: HHT1, HHT2, juvenile polyposis HHT (JP-HHT), clinical HHT with no mutation (either laboratory mutation test was not able to identify a mutation or mutation diagnostics had not been performed). Treatment of PAVM was categorized in five ways: embolization, surgery, surgery and embolization, too small to treat, and treatment offered.

\section{Written advice on epistaxis}

Patients categorized by "written advice not relevant" were excluded from the analysis. This group included patients who were referred having an HHT-mutation, discovered as part of a family investigation but who had never experienced epistaxis and did not want written advice. Data on written epistaxis advice was divided into three categories: no written advice given; written advice given; the patient was 
informed about epistaxis. In the analysis, the two categories "written advice given" and "the patient was informed about epistaxis" were merged into one group.

\section{Assessment on iron deficiency anaemia}

Data on assessment regarding iron deficiency anaemia was divided into two categories; whether iron deficiency anaemia was assessed at the first visit or not.

Data on iron deficiency anaemia was collected in all patients 12 years or older. This age limit was set due to the clinical practise of not routinely taking blood samples in younger children.

Low haemoglobin $(\mathrm{Hgb})$ was defined as followed:

- Adults (>18 years): $\mathrm{Hgb}<8.3 \mathrm{mmol} / \mathrm{L}$ for men, and $\mathrm{Hgb}<7.3 \mathrm{mmol} / \mathrm{L}$ for women

- Children ( $\geq 12-18$ years): $\mathrm{Hgb}<7.8 \mathrm{mmol} / \mathrm{L}$ for boys, and $\mathrm{Hgb}<7.0 \mathrm{mmol} / \mathrm{L}$ for girls

Low ferritin was defined as followed:

- Adults ( $\geq 15$ years): Ferritin $<15 \mu \mathrm{g} / \mathrm{L}$

- Children ( $<15$ years): Ferritin $<12 \mu \mathrm{g} / \mathrm{L}$

\section{Written advice on $A B$ prophylaxis}

Patients categorized by "written advice not relevant" were excluded from this analysis. This included patients who did not have any signs of PAVM at screening. Data on written advice on AB prophylaxis was divided into three categories: no written advice given; written advice given; the patient was informed about AB. In the analysis, the two categories "written advice given" and "the patient was informed about $A B$ prophylaxis" were merged into one group.

\section{Written advice on pregnancy}

VASCERN recommend that all pregnant women with a CT-verified PAVM should receive written advice on pregnancy and $\mathrm{HHT}$. To secure that all potential pregnant women received written advice, the study included all women from the age of 15 to 45 years old. All other patients were categorised as "written advice not relevant" and were excluded from the analysis.

Data on written advice during pregnancy was divided into three categories: no written advice given; written advice given and the patient was informed about HHT pregnancies. In the analysis, the two categories "written advice given" and "the patient was informed about pregnancy" were merged into one group.

\section{Patient interview}


To secure that information provided to the patients was given and understood, The Danish HHT-centre made a small qualitative study. A semi-constructed interview was made to determinate if patients, who had received a pamphlet concerning $\mathrm{HHT}$, were satisfied with the information orally as well as written. In the period from March $24^{\text {th }} 2017$ to March $12^{\text {th }} 2018,11$ patients were interviewed by telephone in order to evaluate their first visit at The Danish HHT-centre.

\section{Statistical analysis}

Reports from the REDCap database were generated and manually extracted into a spreadsheet in Microsoft Excel version 15.18. All data was extracted into two different spreadsheets, independently. The spreadsheets were compared to avoid typing error. All information was anonymised in the spreadsheets.

The percentage of the fulfilment of each outcome measure was calculated for both group I and II (before and after publishing the outcome measures). The outcome measures 1 to 4 for group I and II were then compared using a chi-square-test to determinate a significant difference. Outcome measure 5 for group I and II were compared using Fischer's exact test.

\section{Results}

A full overview of the data can be found in Appendix 3.

\section{Patient characteristics}

A total of 180 patients were included. The mean age at diagnosis was 40.2 years spanning from 2 to 79 years. The patients consisted of 81 men and 99 women. There was no statistically significant difference between group I and group II in any of the five outcome measures. The results are presented as the combined numbers for the two groups. An overview of the results of all outcome measures can be seen in Table 1. 
Table 1

Overview of outcome measures

\begin{tabular}{|c|c|c|c|c|c|}
\hline Outcome measure & Target population & $\begin{array}{l}\text { Cases } \\
(\mathrm{N})\end{array}$ & $\begin{array}{l}\text { Target } \\
\text { threshold }\end{array}$ & Fulfilment & $\begin{array}{l}\text { Target } \\
\text { threshold } \\
\text { achieved }\end{array}$ \\
\hline $\begin{array}{l}\text { 1) Screening for } \\
\text { PAVM }\end{array}$ & All HHT-patients & 180 & $\geq 90 \%$ & $\begin{array}{l}100 \% \\
(n=180)\end{array}$ & Yes \\
\hline $\begin{array}{l}\text { 2) Written advice } \\
\text { on } \\
\text { epistaxis }\end{array}$ & All HHT-patients with epistaxis & 151 & $\geq 90 \%$ & $\begin{array}{l}66 \% \\
(n=99)\end{array}$ & No \\
\hline $\begin{array}{l}\text { 3) Iron deficiency } \\
\text { anaemia } \\
\text { assessment }\end{array}$ & $\begin{array}{l}\text { All HHT-patients, and } \geq 12 \\
\text { years old }\end{array}$ & 167 & $\geq 70 \%$ & $\begin{array}{l}80 \% \\
(n=133)\end{array}$ & Yes \\
\hline $\begin{array}{l}\text { 4) Written advice } \\
\text { on antibiotics }\end{array}$ & $\begin{array}{l}\text { All HHT patients, except } 9 \\
\text { patients where PAVM was } \\
\text { ruled out. }\end{array}$ & 171 & $100 \%$ & $\begin{array}{l}75 \% \\
(n=129)\end{array}$ & No \\
\hline $\begin{array}{l}\text { 5) Written advice } \\
\text { during pregnancy }\end{array}$ & $\begin{array}{l}\text { All HHT-patients, and female } \\
\geq 15 \text { and } \leq 45 \text { years old }\end{array}$ & 45 & $100 \%$ & $\begin{array}{l}80 \% \\
(\mathrm{n}=36)\end{array}$ & No \\
\hline
\end{tabular}

\section{Outcome measure 1: PAVM screening}

A total of 180 patients were included in the analysis. We found that $13 \%(n=24)$ of the patients were already diagnosed with PAVM by a thoracic CT-scan at their first visit, and among the remaining $87 \%$ $(n=156)$ PAVM screening were initiated. A total of $47(26 \%)$ patients received treatment for their PAVM thereby reducing risk for severe complications and 10 patients with PAVM too small for treatment were included in a surveillance programme (Figure 1).

SAT: saturation measurement, TTCE Transthoracic Contrast Echocardiography

Patients with PAVM too small for treatment, are followed to see if the PAVM increase in size.

Surgery was in all cases performed before referral to the HHT-centre

The distribution of patients with one or more PAVM between genotypes can be seen in Table 2 . 
Table 2

Genotypes and PAVM

\begin{tabular}{|lll|}
\hline Genotype & $\begin{array}{l}\text { Number of patients (percentage of the } \\
\text { total population } \mathbf{n = 1 8 0 )}\end{array}$ & $\begin{array}{l}\text { Patients with PAVM identified (percentage } \\
\text { of genotype subgroup) }\end{array}$ \\
\hline HHT1 & $89(49 \%)$ & $38(42.7 \%)$ \\
HHT2 & $67(37 \%)$ & $12(17.9 \%)$ \\
\hline JP-HHT & $15(8 \%)$ & $5(33 \%)$ \\
$\begin{array}{l}\text { Clinical } \\
\text { HHT }\end{array}$ & $9(5 \%)$ & $2(22.5 \%)$ \\
\hline
\end{tabular}

\section{Outcome measure 3: Assessment of iron deficiency and anaemia}

A total of 167 patients were included in the analysis. Eighty percent $(n=133)$ were assessed for iron deficiency and anaemia. In total iron and/or haemoglobin deficiency was identified and treated in 34 patients. Thirteen percent $(n=17)$ had low levels of ferritin, and 13\% $(n=17)$ had low levels of Hgb. In patients with either low ferritin or low Hgb, nine patients had iron deficiency and anaemia simultaneously, which corresponded to $7 \%$.

\section{Patient interview}

All of the 11 patients interviewed by telephone had received at least one pamphlet about HHT, they all stated that they were satisfied with the information they had received.

Furthermore, one patient expressed that it was difficult to get an overview of all the tests and appointments related to the disease.

\section{Discussion}

Although there was a tendency towards more focus on documenting the measures after publication of the outcome measures, this was not statistical significant. We therefore discuss all the results as one unique 5 year group

\section{Outcome measure 1: PAVM screening}

All HHT-patients received a PAVM screening using saturation measurement, a TTCE, or a thoracic CTscan. The most common screening was TTCE performed in $88.8 \%$ of all patients. The reason why this is not $100 \%$ is that children do not receive a TTCE until they are at least 12 years of age, and a few patients declined further screening. A TTCE uses a grading system to categorize the severity of a shunt. Shunts are graded from 0 to 4 , with 4 being the most severe. Studies have shown that an increased shunt grade predicts an increased probability for PAVM $[9,10]$. At the Danish HHT-centre, only patients with a TTCE 
grade of 2, 3 or 4 are offered a thoracic CT-scan, this to reduces the amount of x-ray in patients. We are not aware of PAVM in patients with TTCE grad 0 or 1.

Due to the risk of brain abscess and ischaemic stroke associated to PAVM, detection and treatment of PAVM is important (6). Embolization has been proven to be an effective treatment for PAVM, and is our prefered treatment of choice [11]. We did have 3 patients who had surgery for their PAVM, two of them before they visited our center with 1 needing further embolization therapy. One patient had PAVM and very severe pulmonary hypertension and needed lungtransplantation. In this study we found that all patients with treatable PAVM received treatment.

The prevalence of PAVM among HHT1-patients was $42.7 \%$. This is consistent with Letterboer et al. [12] who found that $48.7 \%$ of all HHT1-patients had PAVM. Among HHT2-patients, the prevalence of PAVM was $17.9 \%$, while Letterboer et al. found a prevalence of $5.3 \%$, and Abdalla et al. [13] found a prevalence of $5 \%$. The reason for this difference is not clarified. In this study, the screening identified 47 patients with PAVM, who were treated to prevent potential life threatening complications.

\section{Outcome measure 3: Assessment of iron deficiency anaemia}

The target threshold of $70 \%$ was achieved as $80 \%$ of the relevant population was assessed. This study investigated whether iron deficiency anaemia was assessed at the first visit, though VASCERN recommend evaluation at every visit. If patients at the Danish HHT-centre have normal ferritin and $\mathrm{Hgb}$ levels at their first visit, they are advised to have assessment of iron deficiency anaemia at their general practitioner (GP) e.g. once a year or if bleeding worsen. We were not able to include results from assessment at the GP in the present study.

Before their first visit at our centre some patients may have had an iron deficiency anaemia assessment at their GP or at a hospital in a region other than the Region of Southern Denmark. This may have caused an underestimation of the number of patients who received an iron deficiency anaemia assessment. Iron and/or haemoglobin deficiency was identified and treated in 43 patients, helping these patients reducing fatigue and achieving a higher level of energy.

\section{Outcome measures 2, 4 and 5: Written advice on epistaxis, $A B$, and pregnancy}

The target threshold for outcome measures 2, 4 and 5 was not achieved in either of the measures. The outcome measures involved written advice. It was difficult to determinate if pamphlets were handed out as there was no procedure for registration. In many cases, the medical journal stated that the patient was thoroughly informed about $\mathrm{HHT}$ in general or about epistaxis, AB prophylaxis or pregnancy specifically but without a firm registration of handing out written advice. In this study, we decided that thoroughly oral information was given together with written advice and we added patients who had thoroughly oral information with those where written advice was documented. This could lead to an overestimation of 
the number of patients who received written advice. Pamphlets are accessible at the HHT-centre and online at the HHT-centre homepage (https://www.ouh.dk/wm487733). However, there is no routine for documenting distribution of pamphlets to the patients. This may lead to an underestimation of the number of patients who have received written advice. If routines were made to document if written advice was given, it would reduce the underestimation and provide a more exact answer on number of patients receiving written advice.

In this study we decided to investigate if female patients between 15 and 45 years of age had received written advice on pregnancy. We chose this age group as most pregnancies occur inside these margins. However, in clinical practice pregnancy is discussed in all relevant cases and written advice given whenever wanted also to women outside of this age group.

\section{Patient interviews}

The patient interviews support that the real number of patients receiving written advice, are higher than found in this study. Furthermore, the patient interviews showed that the patients were satisfied with the information they received. Patients with chronic diseases and low health literacy are more likely to miss appointments and less likely to take care of their diseases and follow their treatment. Therefore, it is important that the patient receive and understand the information given to them. Outcome measure 2, 4, and 5 all involve written advice about the handling of symptoms of the illness and prevention of disease deterioration. Education of patients is very important to help them understand their illnesses and enable them to make appropriate decisions about their health. Handing out pamphlets is a way to educate patients. However, this may not be sufficient. To help patients to navigate in the Danish health care system, a smartphone application (app) "My Hospital" has been developed. This app provides the patients with information about their illness, an overview of their appointments at the hospital, and information about screenings. In the future, the app will hopefully also be able to provide information about results of conducted screenings, blood samples, etc. This app will further help patients manage their illness and entails written information of HHT.

\section{Strengths and limitations}

The strength of this study is inclusion of all patients with HHT registered at the Danish HHT-centre, and the study is representative for HHT-patients in Denmark.

A limitation of this study was that data retrieval from medical journals was performed by only one person. Furthermore, this study relies on accurate recordkeeping concerning handing out written advice. We recommend using the 5 outcome measures, as a help for the clinicians in securing appropriate evaluation for two of the most severe HHT complications and they help to educate patients. However, patients with $\mathrm{HHT}$ should be referred to a HHT-centre for further highly specialised evaluation regarding other aspects of $\mathrm{HHT}$ including mutation diagnostics and information regarding eventual screening for arteriovenous malformations in the brain and the liver.

\section{Conclusion}


The Danish HHT-centre reached the target threshold for outcome measure 1; that $90 \%$ of the patients should receive a PAVM screening. All patients received a PAVM-screening. The screening programme is effective, resulting in high number of patients receiving proper treatment for PAVM. Target threshold for outcome measure 3 ; that $70 \%$ should be assessed for iron deficiency, was also achieved and help identify anemia and iron deficiency. Outcome measures 2,4 , and 5 , regarding that $90 \%$ of the patients should receive written advice on nosebleed; $100 \%$ of the patients should receive written advice on $A B$ prophylaxis, and; $100 \%$ of relevant patients should receive written advice on pregnancy, were not reached by the centre. We aim to fulfil all the outcome measures as we believe they represent valuable information and education of the patients and will increase their quality of life. Therefore, we have developed an app which will help the HHT-patient receive written information at the most convenient time and place. Further, we will focus on education of nurses and doctors and their documentation of information of HHT-patients.

\section{Abbreviations}

AB: Antibiotics

App: Application

AVM: Arteriovenous malformations

CT: Computer tomography

GP: General practitioner

Hgb: Haemoglobin

HHT: Hereditary Haemorrhagic Telangiectasia

OPEN: Odense Patient data Explorative network

PAVM: Pulmonary arteriovenous malformations

REDCap: Research Electronic Data Capture

SAT: Saturation measurement

TTCE: Transthoracic Contrast echocardiography

VASCERN: European Reference Network for Rare Vascular Diseases

\section{Declarations}

\section{Ethics}


All patients have given written consent that their health information may be used to clinical research. Use of the national HHT-database was approved by the Danish Data Protection Agency as of July 9th 2015 (case number: 15/10194) and the Danish Patient Safety Authority (case number: 3-3013-974/1/).

\section{Availability of data and materials}

Data from REDCap are not publicly available due to personal data on patients.

\section{Competing interests}

The authors declare that they have no competing interests.

\section{Funding}

No funding was given.

\section{Authors' contributions}

TH wrote the protocol, collected data, analysed data, and drafted the manuscript. AK assisted the analysis, reviewed the data, and revised the manuscript. MK helped with the study design and revised the manuscript. SB conducted telephone interviews with HHT-patients revised the manuscript. BLA helped with study design and revised the manuscript. All authors read and approved the final manuscript.

\section{References}

1. Kjeldsen AD, Vase P, Green A. Hereditary haemorrhagic telangiectasia: a population-based study of prevalence and mortality in Danish patients. J Intern Med. 1999;245(1):31-9.

2. Al-Samkari H, Albitar HA, Olitsky SE, Clancy MS, lyer VN. Systemic bevacizumab for high-output cardiac failure in hereditary hemorrhagic telangiectasia: an international survey of HHT centers. Orphanet Journal of Rare Diseases. 2019;14(1):256.

3. Shovlin CL, Sodhi V, McCarthy A, Lasjaunias P, Jackson JE, Sheppard MN. Estimates of maternal risks of pregnancy for women with hereditary haemorrhagic telangiectasia (Osler-Weber-Rendu syndrome): suggested approach for obstetric services. BJOG: An International Journal of Obstetrics \& Gynaecology. 2008;115(9):1108-15.

4. European Reference Network for Rare Vascular Diseases. Missions \& action plan 2021 [Available from: http://vascern.eu/about-vascern/ - 1461615813276-1deb4aba-5bc8.

5. Shovlin CL, Buscarini E, Kjeldsen AD, Mager HJ, Sabba C, Droege F, et al. European Reference Network For Rare Vascular Diseases (VASCERN) Outcome Measures For Hereditary Haemorrhagic Telangiectasia (HHT). Orphanet Journal of Rare Diseases. 2018;13(1):136. 
6. Harris PA, Taylor R, Thielke R, Payne J, Gonzalez N, Conde JG. Research electronic data capture (REDCap)-a metadata-driven methodology and workflow process for providing translational research informatics support. J Biomed Inform. 2009;42(2):377-81.

7. OUH OUH. Research 2021 [19/09/2021]. Available from: https://en.ouh.dk/research/open-odensepatient-data-explorative-network/.

8. Shovlin CL, Guttmacher AE, Buscarini E, Faughnan ME, Hyland RH, Westermann CJ, et al. Diagnostic criteria for hereditary hemorrhagic telangiectasia (Rendu-Osler-Weber syndrome). Am J Med Genet. 2000;91(1):66-7.

9. Zukotynski K, Chan RP, Chow CM, Cohen JH, Faughnan ME. Contrast echocardiography grading predicts pulmonary arteriovenous malformations on CT. Chest. 2007;132(1):18-23.

10. van Gent MWF, Post MC, Snijder RJ, Swaans MJ, Plokker HWM, Westermann CJJ, et al. Grading of pulmonary right-to-left shunt with transthoracic contrast echocardiography: does it predict the indication for embolotherapy? Chest. 2009;135(5):1288-92.

11. Andersen PE, Kjeldsen AD. Interventional treatment of pulmonary arteriovenous malformations. World J Radiol. 2010;2(9):339-44.

12. Letteboer TGW, Mager JJ, Snijder RJ, Koeleman BPC, Lindhout D, Ploos van Amstel JK, et al. Genotype-phenotype relationship in hereditary haemorrhagic telangiectasia. J Med Genet. 2006;43(4):371-7.

13. Abdalla SA, Geisthoff UW, Bonneau D, Plauchu H, McDonald J, Kennedy S, et al. Visceral manifestations in hereditary haemorrhagic telangiectasia type 2. J Med Genet. 2003;40(7):494.

\section{Figures}




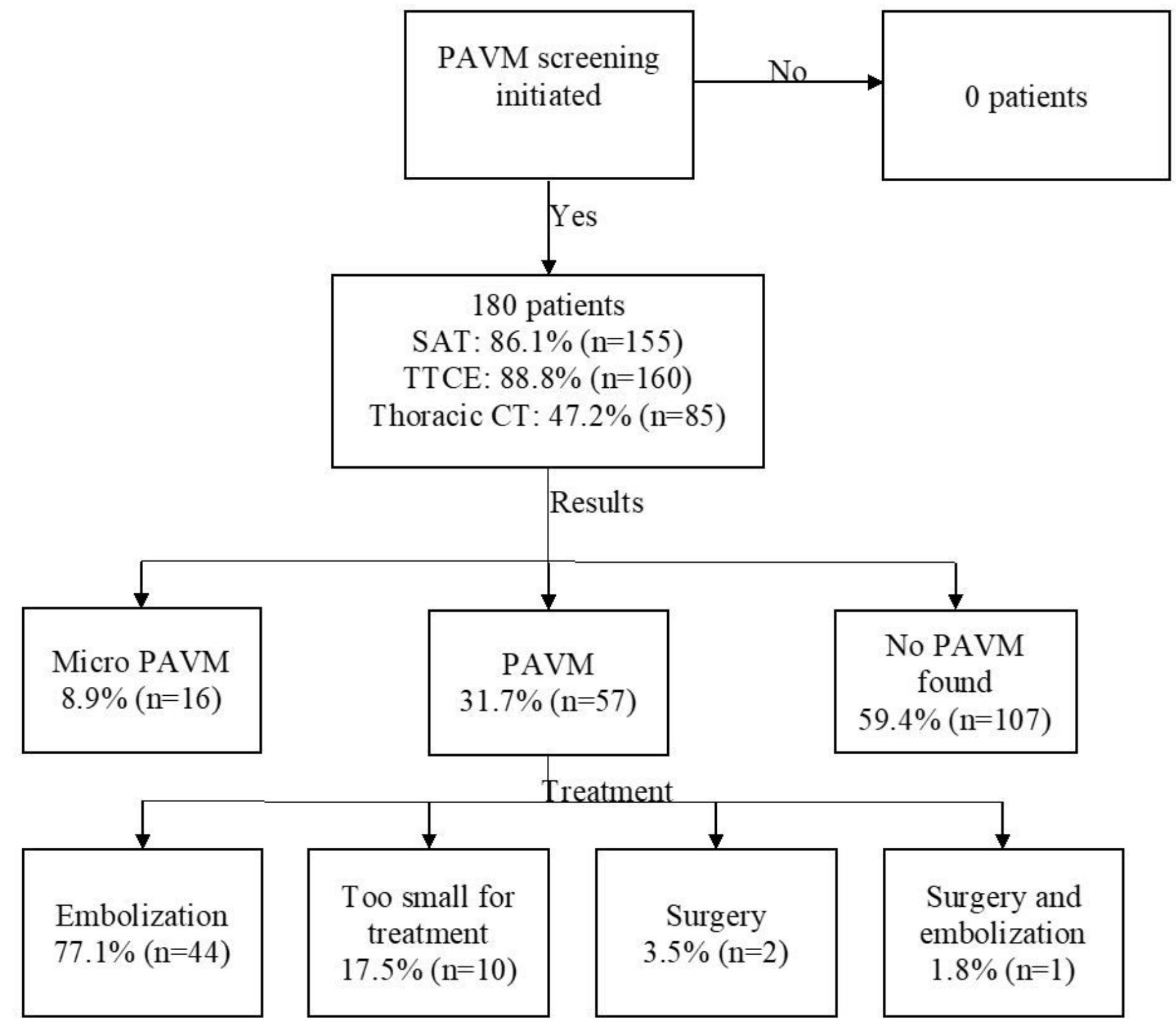

Figure 1

An overview of PAVM screening, the screening results, and the treatment of PAVM. SAT: saturation measurement, TTCE Transthoracic Contrast Echocardiography Patients with PAVM too small for treatment, are followed to see if the PAVM increase in size. Surgery was in all cases performed before referral to the HHT-centre 